\title{
Species-specific accumulation of interspersed sequences in genus Saccharum
}

\author{
Shigeki Nakayama* \\ National Institute of Agrobiological Sciences (NIAS), Tsukuba, Ibaraki 305-8602, Japan
}

(Received 3 December 2004, accepted 14 January 2005)

\begin{abstract}
The genus Saccharum consists of two wild and four cultivated species. Novel interspersed sequences were isolated from cultivated sugar cane $S$. officinarum. These sequences were accumulated in all four cultivated species and their wild ancestral species $S$. robustum, but were not detected in the other wild species $S$. spontaneum and the relative Erianthus arundinaceus. The species-specific accumulation of interspersed sequences would correlate to the domestication of sugar canes.
\end{abstract}

Key words: domestication, interspersed sequences, Saccharum, Sugar cane

Saccharum is the genus of cultivated sugar canes, and belongs to the tribe Andropogoneae together with the genus Zea in the family Poaceae. This genus constitutes the "Saccharum complex" along with the genera Erianthus, Miscanthus, Sclerostachya and Narenga, all of which are considered related to the domestication of sugar cane through the generation of fertile interbred progeny (Guimarães and Sobral 1998). The genus Saccharum consists of six species; two wild species, S. spontaneum and $S$. robustum, and four cultivated species, $S$. officinarum, S. barberi, S. sinense and S. edule (Daniels and Roach 1987). Each species is characterized by floral characters, sugar contents, chromosome numbers and epidermal hair groups, and chromosome numbers of Saccharum species are characterized by both a high level of polyploidy and aneuploidy (Irvine 1999). Phylogenic relationships in the "complex" have been investigated in molecular studies of the cytoplasmic and nuclear DNA (Al-Janabi et al., 1994; Sobral et al., 1994; Guimarães et al., 1997; Ming et al., 1998; Alix et al., 1999; Hodkinson et al., 2002; Lima et al., 2002), and cytological studies on chromosomes (D'Hont et al., 1995; D'Hont et al., 1996; Alix et al., 1998; D’Hont et al., 1998; Piperidis et al., 2000; D'Hont et al., 2002; Cuadrado et al., 2004). In molecular cytological analyses, genus-specific repetitive DNA sequences have been investigated to reveal phylogenic relationships among genera in the "complex" (D'Hont et al., 1995; Alix et al., 1998; Alix et al., 1999), and speciesspecific sequences are required to reveal domestication in the genus Saccharum. The present study describes the isolation of novel interspersed sequences and their species-specific accumulation in Saccharum, and discusses

Edited by Minoru Murata

*Corresponding author. E-mail: shignak@nias.affrc.go.jp the domestication of cultivated sugar cane.

Twelve accessions from eight species of sugar canes and relative species listed in Table 1 were used for this study. Genomic DNA was isolated from young leaves with a DNeasy Plant Mini System (QIAGEN, Germany) according to the manufacturer's directions. Primer sets, RCH2CCS1 (F: TGGCC CGATC TTTCG ATGAG, R: ACTTT CATCT TTATC TAGCA), and SCM (F: ATCCG ACTAC GACGA GCGAA, R550: TGATG AGGAC ACCAC GCGTA, and R180: CAGAA CTCCA CTTTC GAGTG) were used for polymerase chain reaction (PCR) amplification by Ex Taq DNA polymerase (Takara, Japan) with 25 cycles of $94^{\circ} \mathrm{C}$ for $1 \mathrm{~min}, 60^{\circ} \mathrm{C}$ for $40 \mathrm{sec}$ and $72^{\circ} \mathrm{C}$ for 2 min, after an initial denaturation at $94^{\circ} \mathrm{C}$ for $10 \mathrm{~min}$. The primer set RCH2CCS1 was designed to amplify centromeric repeat-sequences based on homologous sequences between rice $\underline{\mathrm{RCH} 2}$ (Dong et al., 1998) and wheat CCS1 (Aragon-Alcaide et al., 1996). Two primer sets, SCM-F and R550, and SCM-F and R180, were designed

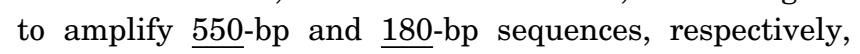
which include homologous sequences between the genome of $\underline{\text { Sugar }}$ Cane and Maize (see below). Amplified DNA sequences were cloned into the pGEM-T easy vector system with the $E$. coli DH5 alpha strain (Promega, WI), isolated by miniprep with a QIAprep spin Miniprep Kit (QIAGEN), and sequenced with a CEQ2000XL (Beckman Coulter, CA) according to the manufacturers' directions. Labeling by PCR and Southern hybridization were carried out as previously described (Nakayama et al., 2001). Chromosomal preparations for FISH were obtained by enzyme maceration from root tips after two hours treatment with a $0.05 \%$ colchicine solution at $25^{\circ} \mathrm{C}$. FISH procedures were carried out as reported (Okada et al., 2000; Nakayama et al., 2004). The biotin-labeled probe was detected with Alexa 488-streptavidin (Molecular 
Table 1. Sugar canes and related species employed in this study. *

\begin{tabular}{cll}
\hline \hline No.** & Species & Accessions \\
\hline 1. & Saccharum edule & IN95-0009 \\
2. & S. robustum & IN84-111 \\
3. & S. officinarum & Badila \\
4. & & Ogasawara \\
5. & S. sinense & Ohshima \\
6. & & Teckcha \\
7. & S. barberi & Chunnee \\
8. & S. spontaneum & Glagah Kloet \\
9. & & SES205 \\
10. & & Ishigaki-39 \\
11. & Erianthus arundinaceus & $28 N G 7$ \\
12. & Zea mays & CI64 \\
\hline
\end{tabular}

* Sugar cane plants were grown in a domed green house of NIAS at Tsukuba, Japan.

** Lane number in Fig. 2

Probes, OR) after tyramide signal amplification (Perkin Elmer, MA), and the DIG-labeled probe was detected with anti-digoxigenin-rhodamine (Roche Diagnostics, Germany) and Alexa 546 donkey anti-sheep IgG (Molecular Probes).

Three bands of PCR products, 1.5-, 2.2-, and 2.8-kbp, were obtained from genomic DNA of $S$. officinarum cv. Badila with the RCH2CCS1 primer set (data not shown). Predicted 240-bp products were amplified from genomic DNA of $O$. sativa cv. Nipponbare with this primer set. Instead of the 240-bp products, PCR amplified these products from $S$. officinarum. Sequence analysis revealed that a cloned 1.5-kbp PCR product consisted of two characteristic parts (Fig. 1A). One part is about 900-bp long and appears related to the centromeric regions, because it showed homology to the centromeric retrotransposon, $\mathrm{CR}$, and the centromeric repeat-sequences in Poaceae (Jiang et al., 1996; Ananiev et al., 1998; Dong et al., 1998; Nonomura and Kurata 1999; Zhong et al., 2002; Jiang et al., 2003). The other part is about 550-bp in length and includes sequence homologous to the genome of maize, and 180-bp of this part appeared very frequently in the maize genome.

In the $S$. officinarum genome, the present status of the 550 -bp sequence was investigated. PCR amplification of 550-bp sequences with the primer set SCM-F and R550, which were designed to amplify the whole of the 550-bp sequence, gave 550-bp products from genomic DNA of $S$. officinarum cv. Badila (Fig. 2A lane 3). PCR amplification of the 180-bp sequence with the primer set SCM-F and R180 yielded $180-\mathrm{bp}, 1.0-\mathrm{kbp}$ and faint 2.0 -kbp products from $S$. officinarum (Fig. 2B lane 3). Sequence analysis revealed that the cloned $1.0-\mathrm{kbp}$ product contained both 180-bp and 550-bp sequences, and the second

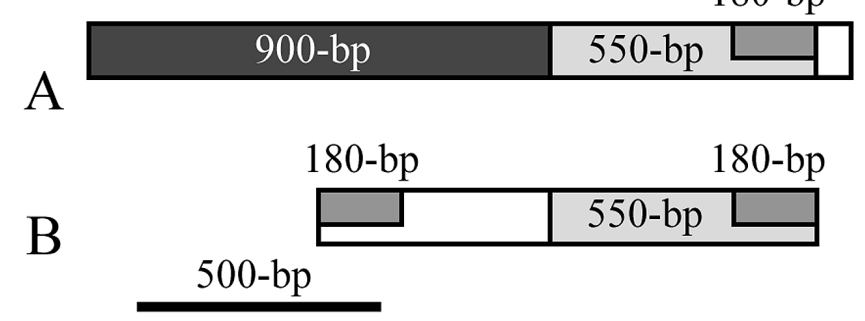

Fig. 1. Scheme of sequences of cloned PCR products. (A) 1.5$\mathrm{kb}$ products obtained with the RCH2CCS1 primer set. (B) 1.0 $\mathrm{kb}$ products obtained with the SCM-F and R180 primer set. Nucleotide sequence data are available in the DDBJ / EMBL / GenBank databases under accession numbers AB197933 and AB197934.

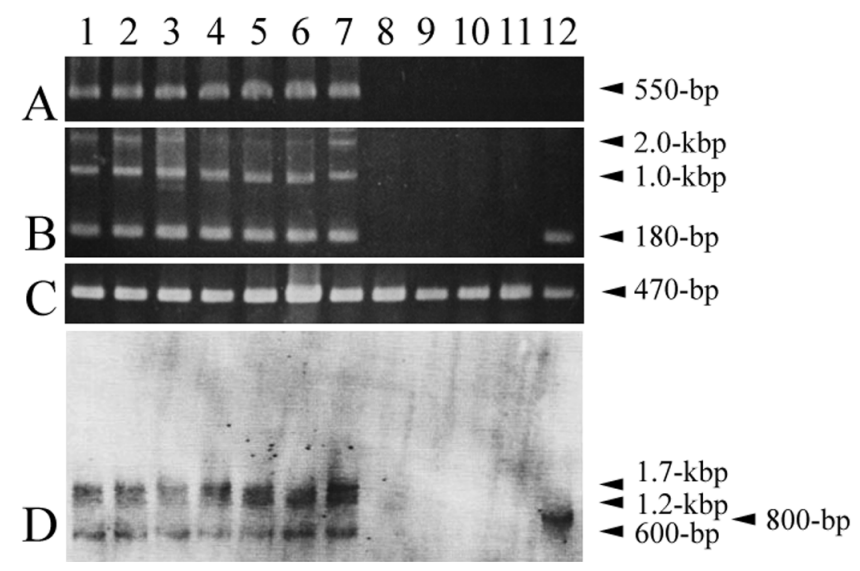

Fig. 2. Species-specific accumulation of SoIS550 among the genus Saccharum. (A) PCR amplification with SCM-F and R550. (B) PCR amplification with SCM-F and R180. (C) PCR amplification with the 17SrDNA primer set (Nakayama et al., 2001). (D) Southern hybridization of SoIS550 in Alu I-digested genomic DNA. Lane numbers are described in Table 1.

180-bp sequence was included in the 550-bp sequence (Fig. 1B). Southern hybridization of the DIG-labeled 550-bp sequence in Alu I-digested genomic DNA of $S$. officinarum showed three strong signals at $600-\mathrm{bp}, 1.2-\mathrm{kbp}$ and 1.7-kbp (Fig. 2D lane 3). The intensity of the hybridization bands suggested that the 550-bp sequences should be repeated in the $S$. officinarum genome. FISH studies with the 550-bp sequence and centromeric SCEN repeatsequences, amplified by PCR from $S$. officinarum with the primer set SCEN-A and SCEN-B (Nagaki et al., 1998), revealed that signals of the 550-bp sequence were interspersed among $S$. officinarum chromosomes (Fig. 3B) except for heterochromatic condensed regions (in window of Fig. 3B), while signals of SCEN repeat-sequences were observed in centromeric regions of chromosomes (Fig. 3C). Three independent studies indicated that 550-bp sequences were interspersed among $S$. officinarum chromosomes and should not be repeated at particular loci. These interspersed 550-bp sequences were named SoIS550, that is, Saccharum officinarum interspersed 


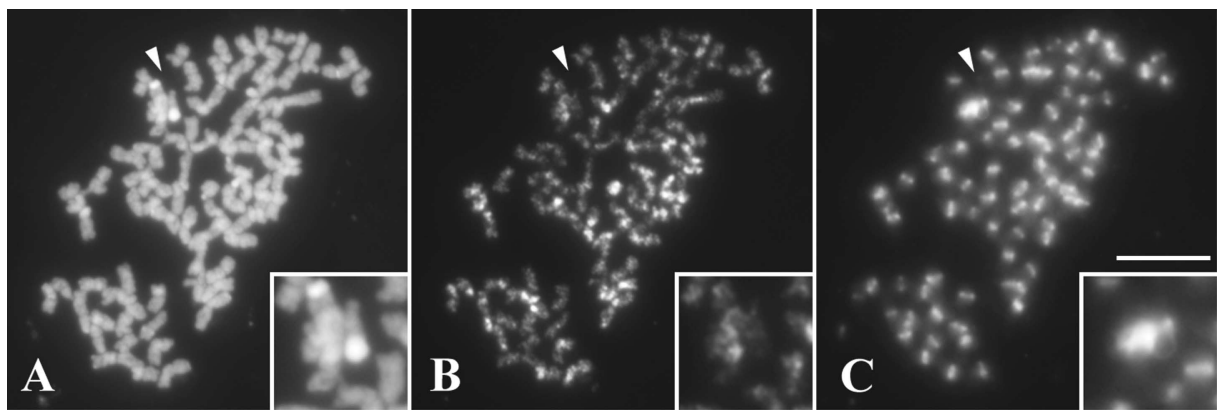

Fig. 3. FISH of SoIS550 on S. officinarum cv. Badila chromosomes. (A) DAPI-stained chromosomes. (B) FISH signals of DIG-labeled SoIS550. (C) FISH signals of biotin-labeled SCEN. In windows: Enlargement of chromosomes with the heterochromatic region indicated by arrowheads. Bar indicates $5 \mu \mathrm{m}$.

sequences of $550-b p$.

The present status of SoIS550 was investigated among six Saccharum species and two relative species in Table 1. PCR amplification with the primer set SCM-F and R550 yielded 550-bp products from genomic DNA of all four cultivated species, $S$. officinarum, $S$. sinense, $S$. barberi, and $S$. edule, and one wild species $S$. robustum, but did not show any products from $S$. spontaneum, E. arundinaceus and $Z$. mays (Fig. 2A), while rDNA sequences were amplified from all species examined (Fig. 2C). PCR amplification with the primer set SCM-F and R180 yielded 180-bp, 1.0-kbp and faint 2.0-kbp products from genomic DNA of five Saccharum species, S. edule, $S$. robustum, S. officinarum, S. sinense, and S. barberi, and only 180-bp products from $Z$. mays, but did not show any products from $S$. spontaneum and $E$. arundinaceus (Fig. 2B). Sizes of PCR products were almost the same among these five Saccharum species. Southern hybridization of DIG-labeled SoIS550 revealed three strong bands at 600 bp, 1.2-kbp and 1.7-kbp in Alu I-digested genomic DNA of five Saccharum species and a band at 800-bp in Z. mays, but did not give any bands in $S$. spontaneum and $E$. arundinaceus (Fig. 2D). Band patterns of Southern hybridization were almost the same among these five Saccharum species. These results indicated that SoIS550 was accumulated in five Saccharum species, but not in S. spontaneum and E. arundinaceus. The similar band patterns of PCR amplification and Southern hybridization among the five species suggested that the present status of SoIS550 should be similar among these species.

The domestication of sugar canes has been examined in various studies (Daniels and Roach 1987; Guimarães and Sobral 1998; Irvine 1999; D'Hont et al., 2002). These reports indicated three important inter-species relationships among the six Saccharum species, that is, (1) wild $S$. robustum would be the ancestor of the two cultivated species $S$. officinarum and $S$. edule, and S. edule would originate from hybridization between $S$. robustum and species in another genus, (2) the other two cultivated species $S$. sinense and $S$. barberi would be hybrids of $S$. officinarum and S. spontaneum, and (3) S. robustum would originate from hybridization between $S$. spontaneum and species in other genus or genera (summarized in Fig. 4). The four domesticated Saccharum species were categorized into two groups, one consisting of $S$. edule and the other comprising $S$. officinarum, $S$. sinense and $S$. barberi. Based on these relationships, wild $S$. robustum was the common ancestral species of the four cultivated species and was key to the domestication of sugar canes, because all cultivated Saccharum species have inherited the genomic DNA of $S$. robustum either directly or indirectly. These relationships and the species-specific accumulation of SoIS550 in this study indicated two hypotheses for the accumulation of SoIS550 in five Saccharum species. The first hypothesis is that the accumulation occurred in $S$. robustum or its ancestral species in another genus, and was inherited by the four cultivated species. The second hypothesis is that the accumulation occurred in the five Saccharum species independently. The similarity of status suggested that the accumulation of SoIS550 occurred before the domestication of the four cultivated species, not independently. The inheritance of the $S$. robustum genome, depicted by the accumulation of SoIS550, supported inter-species relationships among the Saccharum species as reported (Fig. 4).

Detailed sequence analysis of SoIS550 also showed partial homology to a retrotransposon, e.g., B-box and transcribe terminator of rice $p$-SINE1 (Ohtsubo et al., 2004), but other characteristic sequences required to identify a

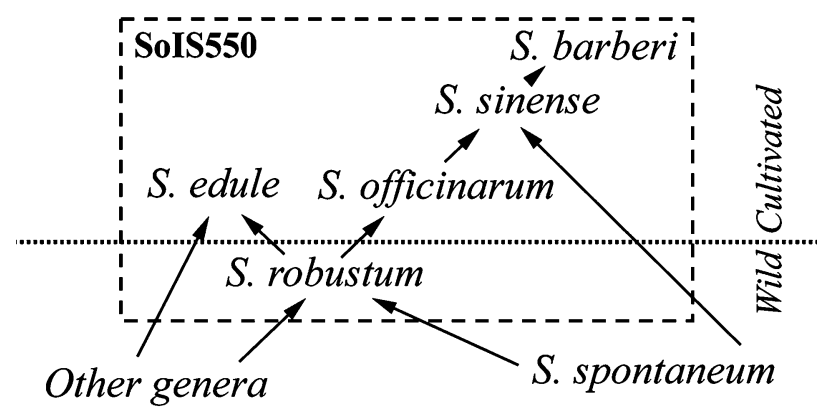

Fig. 4. Phylogenic relationships among the six Saccharum species. 
SINE were not detected in SoIS550. Although the function and the origin of SoIS550 were not revealed in this study, the accumulation of many copies of SoIS550 would have affected the genomic structure of the five Saccharum species. Additionally, the close localization of SoIS550 to centromere-related sequences (Fig. 1A) indicated SoIS550 would have affected centromere function and genomic structure in these Saccharum species. The present study showed that the accumulation of SoIS550 should correlate to domestication in the genus Saccharum.

The author thanks Ms. N. Odashima and Ms. K. Kikuchi (both at NIAS) for excellent technical support, Dr. M. Matsuoka (Japan International Research Center for Agricultural Sciences (JIRCAS), currently at National Agricultural Research Center for Kyushu Okinawa Region) and Dr. M. Sato (JIRCAS) for providing materials and helpful comments, Prof. H. Ohtsubo (U. Tokyo) and Dr. T. Nagamine (NIAS, currently at National Agricultural Research Center for Western Region) for helpful suggestions, and Dr. K. Kadowaki, Dr. S. Takahashi and members of the laboratory of molecular biodiversity of NIAS for support and helpful comments.

\section{REFERENCES}

Al-Janabi, S. M., McClelland, M., Petersen, C., and Sobral,B. W. S. (1994) Phylogenic analysis of organellar DNA sequences in the Andropogoneae: Saccharinae. Theor. Appl. Genet. 88, 933-944.

Alix, K., Baurens, F. C., Paulet, F., Glaszmann, J. C., and D'Hont, A. (1998) Isolation and characterization of a satellite DNA family in the Saccharum complex. Genome 41, 854-864.

Alix, K., Paulet, F., Glaszmann, J. C., and D’Hont, A. (1999) Inter-Alu-like species-specific sequences in the Saccharum complex. Theor. Appl. Genet. 99, 962-968.

Ananiev, E. V., Phillips, R. L., and Rines, H. W. (1998) Chromosome-specific molecular organization of maize (Zea mays L.) centromeric regions. Proc. Natl. Acad. Sci. USA. 95, 13073-13078.

Aragon-Alcaide, L., Miller, T., Schwarzacher, T., Reader, S., and Moore, G. (1996) A cereal centromeric sequence. Chromosoma 105, 261-268.

Cuadrado, A., Acevedo, R., Moreno Diaz de la Espina, S., Jouve, N., and de la Torre, C. (2004) Genome remodelling in three modern $S$. officinarum x $S$. spontaneum sugarcane cultivars. J. Exp. Bot. 55, 847-854.

D'Hont, A., Grivet, L., Feldmann, P., Rao, S., Berding, N., and Glaszmann, J. C. (1996) Characterisation of the double genome structure of modern sugarcane cultivars (Saccharum spp.) by molecular cytogenetics. Mol. Gen. Genet. 250, 405-413.

D'Hont, A., Ison, D., Alix, K., Roux, C., and Glaszmann, J. C. (1998) Determination of basic chromosome numbers in the genus Saccharum by physical mapping of ribosomal RNA genes. Genome 21, 221-225.

D'Hont, A., Paulet, F., and Glaszmann, J. C. (2002) Oligoclonal interspecific origin of 'North Indian' and 'Chinese' sugarcanes. Chromosome Res. 10, 253-262.

D'Hont, A., Rao, S., Feldmann, P., Grivet, L., Islam-Faridi, M. N., Taylor, G., and Glaszmann, J. C. (1995) Identification and characterization of sugarcane intergeneric hybrids, Saccharum officinarum $\mathrm{x}$ Erianthus arundinaceus, with molecular markers and DNA in situ hybridisation. Theor. Appl. Genet. 91, 320-326.

Daniels, J., and Roach, B. T. (1987) Taxonomy and evolution. In: Sugarcane improvement through breeding (ed.:D. J. Heinz), pp 7-84, Elsevier, Amsterdam.

Dong, F., Miller, J. T., Jackson, S. A., Wang, G. L., Ronald, P. C., and Jiang, J. (1998) Rice (Oryza sativa) centromeric regions consist of complex DNA. Proc. Natl. Acad. Sci. USA. 95, 8135-8140.

Guimarães, C. T., Sills, G. R., and Sobral, B. W. S. (1997) Comparative mapping of Andropogoneae: Saccharum L. (sugarcane) and its relation to sorghum and maize. Proc. Natl. Acad. Sci. USA. 94, 14261-14266.

Guimarães, C. T., and Sobral, B. W. S. (1998) The Saccharum complex: Relation to other Andropogoneae. In: Plant Breeding Reviews Vol. 16 (eds.:J. Janick), pp 269-288, John Wiley \& Sons, Hoboken.

Hodkinson, T. R., Chase, M. W., Lledo, M. D., Salamin, N., and Renvoize, S. A. (2002) Phylogenetics of Miscanthus, Saccharum and related genera (Saccharinae, Andropogoneae, Poaceae) based on DNA sequences from ITS nuclear ribosomal DNA and plastid trnL intron and trnL-F intergenic spacers. J. Plant Res. 115, 381-392.

Irvine, J. (1999) Saccharum species as horticultural classes. Theor. Appl. Genet. 98, 186-194.

Jiang, J., Birchler, J. A., Parrott, W. A., and Dawe, K. D. (2003) A molecular view of plant centromeres. Trends Pl. Sci. 8, 570-575.

Jiang, J., Nasuda, S., Dong, F., Scherrer, C. W., Woo, S. S., Wing, R. A., Gill, B. S., and Ward, D. C. (1996) A conserved repetitive DNA element located in the centromeres of cereal chromosomes. Proc. Natl. Acad. Sci. USA. 93, 14210-14213.

Lima, M. L., Garcia, A. A., Oliveira, K. M., Matsuoka, S., Arizono, H., De Souza, C. L., Jr., and De Souza, A. P. (2002) Analysis of genetic similarity detected by AFLP and coefficient of parentage among genotypes of sugar cane (Saccharum spp.). Theor. Appl. Genet. 104, 30-38.

Ming, R., Liu, S.-C., Lin, Y.-R., da Silva, J., Wilson, W., Braga, D., van Deynze, A., Wenslaff, T. F., Wu, K. K., Moore, P. H., Burnquist, W., Sorrells, M. E., Irvine, J. E., and Paterson, A. H. (1998) Detailed alignment of Saccharum and Sorghum chromosomes: Comparative organization of closely related diploid and polyploid genomes. Genetics 150, 1663-1682.

Nagaki, K., Tsujimoto, H., and Sasakuma, T. (1998) A novel repetitive sequence of sugar cane, SCEN family, locating on centromeric regions. Chromosome Res. 6, 295-302.

Nakayama, S., Fujishita, M., and Ohyama, K. (2004) FISH shows structural differentiation between liverwort sex chromosomes. In: Plant Genome: Biodiversity and Evolution. Vol. 2A Lower groups (eds.: A. K. Sharma, and A. Sharma), pp 235-246, Science Publishers, Enfield.

Nakayama, S., Fujishita, M., Sone, T., and Ohyama, K. (2001) Additional locus of rDNA sequence specific to the X chromosome of the liverwort, Marchantia polymorpha. Chromosome Res. 9, 469-473.

Nonomura, K. I., and Kurata, N. (1999) Organization of the 1.9$\mathrm{kb}$ repeat unit $\mathrm{RCE} 1$ in the centromeric region of rice chromosomes. Mol. Gen. Genet. 261, 1-10.

Ohtsubo, H., Cheng, C., Ohsawa, I., Tsuchimoto, S., and Ohtsubo, E. (2004) Rice retroposon $p$-SINE1 and origin of cultivated rice. Breed. Sci. 54, 1-11.

Okada, S., Fujisawa, M., Sone, T., Nakayama, S., Nishiyama, R., Takenaka, M., Yamaoka, S., Sakaida, M., Kono, K., Taka- 
hama, M., Yamato, K. T., Fukuzawa, H., Brennicke, A., and Ohyama, K. (2000) Construction of male and female PAC genomic libraries suitable for identification of Y-chromosome-specific clones from the liverwort, Marchantia polymorpha. Plant J. 24, 421-428.

Piperidis, G., Christopher, M. J., Carroll, B. J., Berding, N., and D'Hont, A. (2000) Molecular contribution to selection of intergeneric hybrids between sugarcane and the wild species Erianthus arundinaceus. Genome 43, 1033-1037.
Sobral, B. W. S., Braga, D. P. V., LaHood, E. S., and Keim, P. (1994) Phylogenic analysis of chloroplast restriction enzyme mutations in the Saccharinae Griseb. subtribe of the Andropogoneae Dumort. tribe. Theor. Appl. Genet. 87, 843-853.

Zhong, C. X., Marshall, J. B., Topp, C., Mroczek, R., Kato, A., Nagaki, K., Birchler, J. A., Jiang, J., and Dawe, R. K. (2002) Centromeric retroelements and satellites interact with maize kinetochore protein CENH3. Plant Cell 14, 28252836. 